\title{
ABDOMEN ULTRASONOGRAPHIC EXAMINATION ANALYSIS IN THE CASE OF URINARY BLADDER DIVERTICULA AT CILEGON HOSPITAL
}

\author{
Tirta Wirya ${ }^{1}$, Gando Sari², Syamsul Bahri ${ }^{3}$, Nursama Heru ${ }^{4}$, Resa Wantika \\ Utami ${ }^{5}$ \\ Teknik Radiodiagnostik dan Radioterapi \\ Politeknik Kesehatan Kementerian Kesehatan Jakarta II \\ Jl. Hang Jebat III/F3 Kebayoran Baru, Jakarta Selatan, 121201-5 \\ e-mail: resawantika3@gmail.com
}

\begin{abstract}
Diverticulum is outpouching of hollow (or fluid-filled) structures, which can form in various organs in the body. Increased intravesical pressure (3-5 times) causes the bladder mucosa to infiltrate itself between the bladder muscle bundles which results in the development of extravasational sacs or saccules which subsequently results in diverticulum formation. The sonographic diagnosis of bladder diverticula depends on the demonstration of communication between the bladder and the mass. When such communication, or estuary, is not seen during ultrasound examination, the bladder diverticulum can look like any other type of cystic pelvic mass.

The approach used is descriptive qualitative. This study aims to analyze the examination of the USG Abdomen with clinical bladder diverticula to get an appropriate picture of USG so that the diagnosis can be established. The study population was patients who performed an abdominal USG examination at the Cilegon Regional General Hospital. The sample of this study were 1 (one) patient. The method used in collecting data in this study is observation, documentation, and literature study.
\end{abstract}

Keywords: Ultrasound, Urinary Bladder, Diverticula

\section{INTRODUCTION}

USG (Ultrasonography) is a medical diagnostic support that uses sound waves with high frequencies ranging from $2 \mathrm{MHz}$ to 10 $\mathrm{MHz}^{1}$. And in Indonesia, ultrasound examinations have been known and carried out since the 1970s.

Ultrasonography (USG) is one of the imaging modalities studied in the field of radiology, diagnosis using ultrasound has many advantages over other modalities ${ }^{2,3}$. Such as the examination is non-invasive, inexpensive, easy, can be done anywhere, is safe because it does not have the effect of radiation, and produces fast information ${ }^{4}$. One example of an ultrasound examination that is usually done is the Abdomen examination. In general, the organs that can be evaluated include the liver, gallbladder, kidneys, aorta, spleen, bladder, prostate, and uterus. Ultrasound Abdomen is most often used because it is cheaper and is non-ionizing. Ultrasound examination is very safe to do for adults, children or mothers who are pregnant and many clinics that can be found using the help of ultrasound, one of which is liver cirrhosis ${ }^{5}$.

Ultrasound examination in general is an ultrasound examination of the abdomen, ultrasound of the abdomen is done to see any abnormalities in the abdominal cavity. One of the abnormalities in the abdominal cavity occurs in the urinary bladder. With the help of ultrasound we can find abnormalities in the urinary bladder, one of which is a diverticula. 
The diverticulum is the outpouching of hollow (or fluid-filled) structures, which can form in various organs in the body. The increase in intravesical pressure (3-5 times) causes the bladder mucosa to infiltrate itself between the muscle bundles of the bladder resulting in the development of an extravasational sac or saccule of the mucosa which in turn results in the formation of the diverticulum. Regarding the site of diverticulum formation, the area most likely to be affected is the area adjacent to the ureteral opening where longitudinal muscle fibers are absent and facilitate diverticulum formation ${ }^{6}$. Bladder diverticula are congenital or acquired in adulthood. The incidence of congenital bladder diverticula is reported to be $1.7 \%$ and peaks in children under 10 years. $90 \%$ are located superolateral to the ureteric opening near the ureterovesical junction ${ }^{7}$.

Diverticula in the bladder are bladder mucosa that lacks a muscular layer resulting in loss of contractile activity which will eventually lead to urinary stasis. This will later manifest as stone formation and urinary tract infection which predisposes to malignancy. Faysal $\mathrm{MH}$ and Freiha FS concluded that carcinogenic stasis in the bladder diverticula predisposes the bladder epithelium to neoplasm formation. Shakeri $\mathrm{S}$ et al. and Dondalsky $\mathrm{M}$ et al. reported that $2-7 \%$ of patients with diverticula in the bladder had neoplasms inside the diverticula ${ }^{6}$.

Bladder diverticula are protrusions of the bladder mucosa that herniate through the detrusor muscle fibers to form a periveical cystic mass. The identity of this mass is usually evident on contrast radiographs, but may be obscured by routine pelvic sonographic imaging. Such ambiguity is partly due to the very variable sonographic imaging of diverticula or not because there is often no apparent connection or passage from the urinary bladder to the diverticula ${ }^{8}$. We described a series of perivesicular masses that caused initial interpretive confusion but were eventually confirmed to be bladder diverticula after various ultrasound imaging maneuvers.

\section{METHOD}

In this research, the approach used is descriptive qualitative. This study aims to analyze the clinical abdominal ultrasound examination with a bladder diverticula. The population of this study were patients who underwent abdominal ultrasound examinations at the Cilegon Regional General Hospital. The sample of this study was 1 (one) patient. The methods used in collecting data in this study are observation, documentation, and literature study.

\section{RESULT}

The data obtained during the observation, the patient Ny. M, 57 years old, conducted an examination at the Radiology Installation to perform an ultrasound examination of the abdomen with clinical bladder diverticula based on a referral from an internal medicine specialist. The patient makes an appointment when registering at the Radiology administration, the officer schedules an examination on Thursday 12 March 2020.

\section{Patient Preparation}

Inpatients who have been scheduled and have made preparations, namely fasting 7 - 8 hours and holding back urine before the examination, come to the radiology accompanied by the nurse ${ }^{9}$. Then the patient is positioned supine on the examination table

\section{Examination Technique}

This examination uses a sector transducer with 
3-5 $\mathrm{MHz}$, then perform routine abdominal examinations as usual starting from taking the liver, gallbladder, pancreas, kidneys and lymph nodes. Then what will be focused on this time is the pelvis, more precisely the bladder. When the mass in the pelvis is visible and the origin of the mass is not visible, additional maneuvers are required to visualize the origin of the structure. The examination is performed transabdominally with the urine filled bladder as an acoustic window ${ }^{10}$. The diagnosis of the mass as a bladder diverticulum is confirmed when communication or passage between the mass and the bladder is visualized.

Diverticula can be mistaken for other lesions for several reasons. First, the tube with the bladder may be small and narrow. Such a narrow channel resolution will be substantial when scanning has to occur at very high depths or when the scanning perspective is limited to those where the sound rays are parallel to the channel walls. Second, the narrow opening can interfere with emptying of the diverticulum, leading to bladder stasis and urinary tract infections. This can change the echogenicity of the urine filling the diverticulum and thereby obscure its cystic character. In the same way, stones, blood, and tumors can form inside the diverticula and create a complex-looking mass.

Third, the formation of a diagnosis can be greatly influenced by underfilling or overfilling of the bladder. Usually, an increase in intravesicular pressure causes the diverticular duct to open up so that it is obvious. Such an increase in pressure can be accomplished by filling the bladder to capacity. The identification of the diverticulum depends on how accurately we identify the bladder. Very large diverticula can be mistaken for a bladder, especially if the bladder is actually deflated. Increase the opportunity to demonstrate the canal walls of the diverticulum, such as scanning from multiple perspectives to get a clear view of the diverticulum channels (Figure 1) so that the diagnosis can be made accurately.

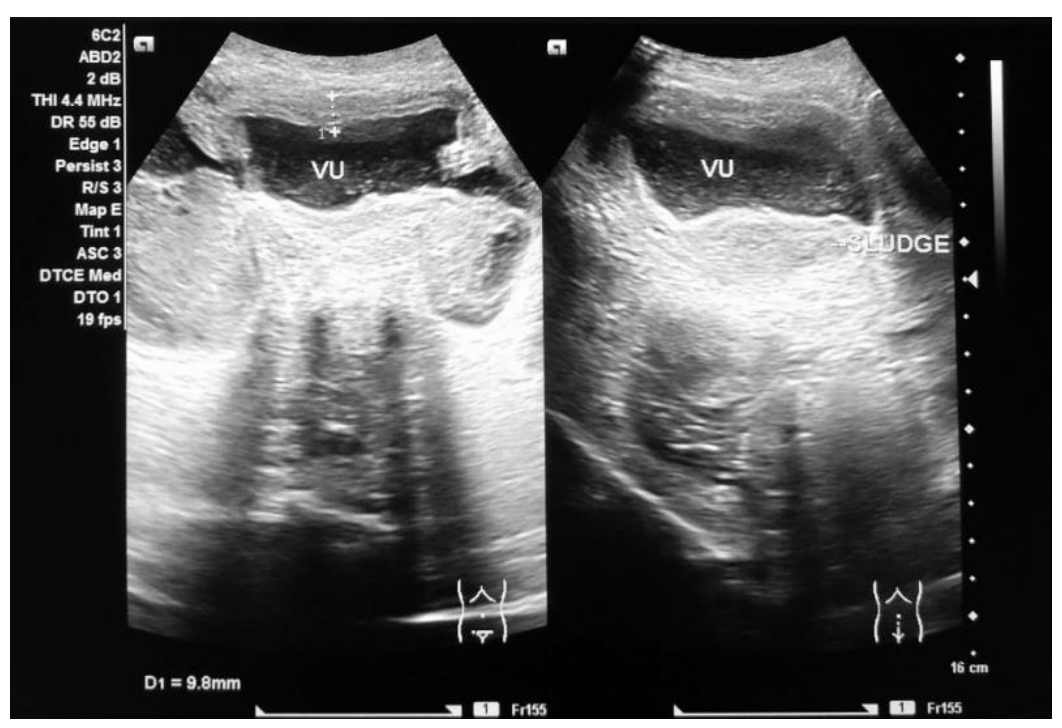

Figure 1. Diverticula appear and their connection to the bladder with thickening of the walls and sludge. 


\section{CONCLUSION}

The sonographic diagnosis of bladder diverticula depends on the demonstration of communication between the bladder and the mass. When such communication, or estuary, is not visible on ultrasound, the bladder diverticulum can appear like other types of cystic pelvic masses.

So, we recommend that to diagnose bladder diverticula it should be scanned from multiple transabdominal perspectives to visualize its connection to the bladder. Display of the biological diverticulum urine can change in response to various maneuvers. When deprived of urine, diverticula often contain internal echoes that make them appear complex, complex, or even solid. With more filling of urine and open communication with the bladder, the true cystic character of the diverticulum becomes clearer.

\section{REFERENSI}

1. Brooks A, Connolly J, Chan O. Ultrasound in Emergency Care. Ultrasound in Emergency Care. Pennsylvania; 2008. 1-154 p.

2. Imardi S, Ramli K. Pengembangan Dan Pengkayaan Fungsi Antarmuka Perangkat Lunak Untuk Visualisasi Dan Analisis Citra Ultrasonografi. Fak Tek Univ Indones. :1-10.

3. Beuscher-Willems B, Brugman L, Gorg C, Grebe T, Grenier L. Ultrasound. New York: Thieme Clinical Companions; 2007.

4. Majdawati A. Hubungan gambaran ultrasonografi ginjal dengan laju Filtrasi Glomerulus ( GFR ) pada penderita gangguan ginjal Correlation betwen renal ultrasound examination and Glomerular Filtration Rate in renal disease patient. J Kedokt Yars. 2009;17(1):74-81.

5. Irawan E. Deteksi Penyakit Apendicitis dari Hasil Ultrasonografi ( USG) Dengan Menggunakan Metode Tresholding dan Edge Detection ( CANNY). Fak IImu Keperawatan Univ BSI. 2014;(1):85-94.

6. Prakash, Rajini T, Bhardwaj AK, Jayanthi V, Kalyani Rao P, Singh G. Urinary bladder diverticulum and its association with malignancy: An anatomical study on cadavers. Rom J Morphol Embryol. 2010;51(3):5435.

7. Gómez-Contreras DE, Pinzón-Uresti MA, Barragán-Albo F, Rodríguez-Balderrama I. Congenital bladder diverticulum in a newborn: A case report. Rev Mex Urol. 2018;78(1):40-3.

8. Maynor CH, Kliewer MA, Hertzberg BS, Paulson EK, Keogan MT, Carroll BA. Urinary bladder diverticula: Sonographic diagnosis and interpretive pitfalls. J Ultrasound Med. 1996;15(3):189-94.

9. Palmer PE. PES PALMER MANUAL OF DIAGNOSTIC ULTRASOUND.pdf. 1995.

10. Block B. Color Atlas of Ultrasound Anatomy [Internet]. Vol. 184, Ultrasound. 2004. 296 p. Available from: http://www. ajronline.org/cgi/content/full/184/4/1371 